06

\title{
Формирование наночастиц серебра и углеродных квантовых точек при лазерном фотолизе нитрата серебра в поливиниловом спирте
}

\author{
() А.И. Сидоров, ${ }^{1,2}$ А.А. Ефримов, ${ }^{2}$ В.П. Цепич ${ }^{2}$ \\ ${ }^{1}$ Университет ИТМО, \\ 97101 Санкт-Петербург, Россия \\ ${ }^{2}$ Санкт-Петербургский государственный электротехнический университет „ЛЭТИ“, \\ 197376 Санкт-Петербург, Россия \\ e-mail: idorov@oi.ifmo.ru
}

Поступило в Редакцию 16 февраля 2021 г.

В окончательной редакции 16 марта 2021 г.

Принято к публикации 20 марта 2021 г.

\begin{abstract}
Представлены результаты исследования фотолиза нитрата серебра в растворе поливинилового спирта под действием непрерывного лазерного излучения с длиной волны $405 \mathrm{~nm}$. Показано, что при лазерном воздействии на поверхности подложки формируются наночастицы серебра, обладающие плазмонным резонансом, и углеродные квантовые точки, обладающие люминесценцией. Средний размер наночастиц серебра составлял 10-50 nm. При высокой дозе облучения они образуют трехмерные фрактальные кластеры.
\end{abstract}

Ключевые слова: фотолиз, лазерное облучение, наночастица, квантовая точка, серебро, углерод.

DOI: $10.21883 /$ JTF.2021.08.51101.40-21

\section{Введение}

Наночастицы металлов широко используются в фотонике и наноплазмонике для записи оптической информации, в оптических измерениях, сенсорике, устройствах, основанных на усилении люминесценции и рамановского рассеяния. К таким устройствам относятся волноводы с оболочкой из металлических наночастиц [1], химические [2] и биосенсоры [3,4], плазмонные волноводы [5], наноантенны [6] и оптические нанотранзисторы [7], метаматериалы [8], концентраторы электромагнитного поля [9], оптические композиты [10], плазмонные фотонные кристаллы [11] и другие устройства наноплазмоники [12,13]. В устройствах наноплазмоники на основе металлических наночастиц в основном используются наночастицы серебра, золота и меди, так как они обладают наиболее интенсивными плазмонными резонансами в видимой области спектра $[14,15]$. Наночастицы металлов могут быть сформированы в жидких или полимерных средах методами химического синтеза [16,17], на поверхности подложки методами лазерной абляции и лазерного испарения [18-20], методом вакуумного напыления [21] и термообработкой стекол, содержащих ионы металла, в восстановительной атмосфере [22,23].

Металлические микро- и наноструктуры могут быть использованы для создания метаматериалов [24,25], проводников для оптоэлектронных устройств $[26,27]$ и сенсорных устройств микрофлюидики [26,28]. Существует много способов создания $2 D$ - и $3 D$-металлических микро- и наноструктур. К ним, в частности, можно отнести двухфотонную фоторедукцию с использованием фемтосекундных лазеров [26-34]. В работе [35] показано, что при воздействии непрерывного сфокусированного лазерного излучения на раствор желатина, содержащий ионы серебра, происходит восстановление серебра и образование наночастиц. Перемещение лазерного луча дает возможность формировать микропроводники из серебра на поверхности диэлектриков.

Целью настоящей работы было исследование особенностей формирования наночастиц серебра при фотолизе нитрата серебра в поливиниловом спирте непрерывным лазерным излучением с длиной волны $405 \mathrm{~nm}$.

\section{1. Методики экспериментов}

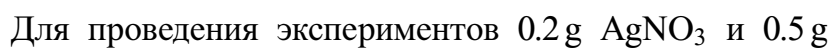
поливинилового спирта (ПВС) с относительной молекулярной массой 25000 растворялись в $5 \mathrm{ml}$ воды, нагретой до $60^{\circ} \mathrm{C}$. Каплю приготовленного раствора помещали на стеклянную подложку и облучали снизу сфокусированным лазерным излучением с длиной волны $405 \mathrm{~nm}$. Для облучения был использован непрерывный полупроводниковый лазер KLM-405-5 мощностью $50 \mathrm{~mW}$. Следует отметить, что длина волны лазера совпадает с полосой поглощения, связанной с плазмонным резонансом сферических наночастиц серебра на стекле $[14,15]$. Доза облучения D варьировалась в пределах 4-40J/mm². Длительность облучения при этом составляла 1-10 min. Диаметр лазерного луча на поверхности стекла был выбран равным $1 \mathrm{~mm}$ для удобства оптических измерений. Диафрагма при фокусировке лазерного луча не использовалась. После облучения образцы помещали в воду для удаления ПВС. Затем образцы высушивались.

Спектры оптической плотности измерялись с помощью спектрофотометра Lambda 650 (Perkin Elmer). Для измерения спектров люминесценции использовался 
спектрофлуориметр LS-55 (Perkin Elmer). Все спектральные измерения проводились при комнатной температуре. Изображения наночастиц серебра, а также энергодисперсионные спектры были получены с помощью сканирующего электронного микроскопа Zeiss Merlin.

\section{2. Результаты}

На рис. 1 показана фотография облученного участка стекла. Из рисунка видно, что облученная зона приобрела красный оттенок. Неравномерное распределение окраски в облученной зоне связано с неравномерным распределением мощности в поперечном сечении лазерного луча. Вокруг облученной зоны наблюдается светложелтый ореол.

На рис. 2 показаны спектры оптической плотности облученных участков стекла. Для $D=4 \mathrm{~J} / \mathrm{mm}^{2}$ в спектре присутствует узкая полоса поглощения с максимумом на длине волны $405 \mathrm{~nm}$. Данная полоса поглощения соответствует плазмонному резонансу сферических наночастиц серебра, имеющих размер менее $20 \mathrm{~nm}[14,15]$. Для $D=20 \mathrm{~J} / \mathrm{mm}^{2}$ происходит увеличение амплитуды плазмонной полосы поглощения, ее уширение и длинноволновый спектральный сдвиг ее максимума. При дальнейшем увеличении дозы облучения происходит дальнейшее увеличение амплитуды плазмонной полосы, еe уширение и длинноволновый сдвиг. Кроме того, возникает еще одна полоса поглощения вблизи $360 \mathrm{~nm}$. Увеличение дозы облучения сопровождается также увеличением пьедестала спектральных зависимостей оптической плотности. Вблизи облученной зоны, но вне ее, также наблюдается узкая плазмонная полоса поглощения (кривая 4 на рис. 2). Это указывает на то, что вне облученной зоны также возникают наночастицы серебра.

Энергодисперсионный спектр облученного участка образца показан на рис. 3. В спектре присутствуют пики,

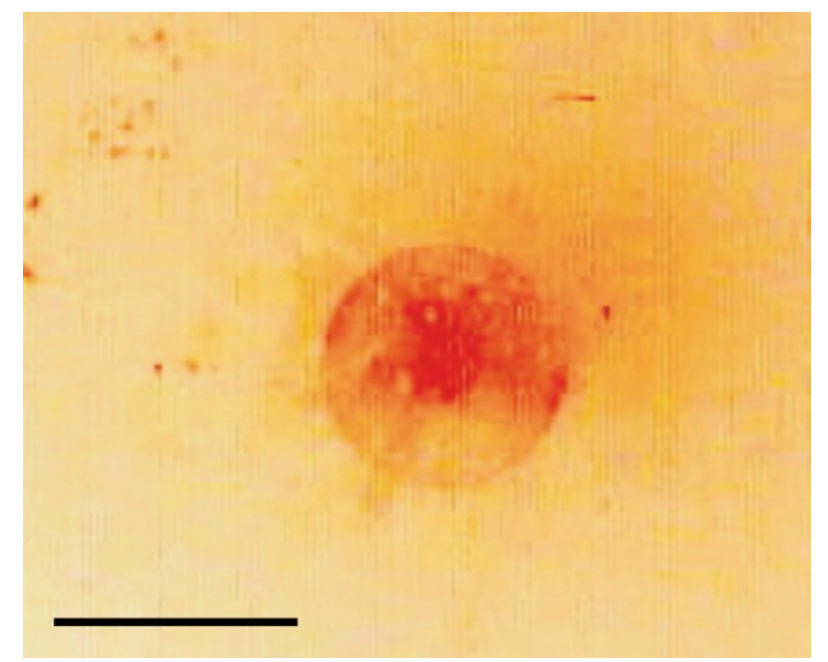

Рис. 1. Фотография облученного участка стекла. $D=20 \mathrm{~J} / \mathrm{mm}^{2}$. Масштаб $-1 \mathrm{~mm}$.

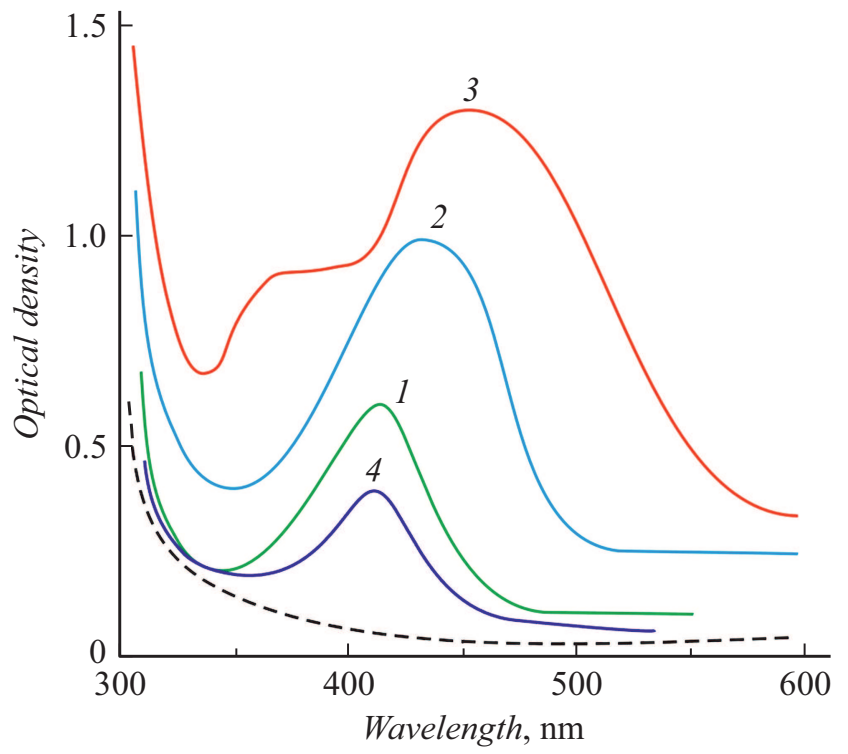

Pис. 2. Спектры оптической плотности облученных участков стекла. $1-D=4 \mathrm{~J} / \mathrm{mm}^{2}, 2-20,3-40 ; 4-$ стекло вблизи облученной зоны. $D=20 \mathrm{~J} / \mathrm{mm}^{2}$.

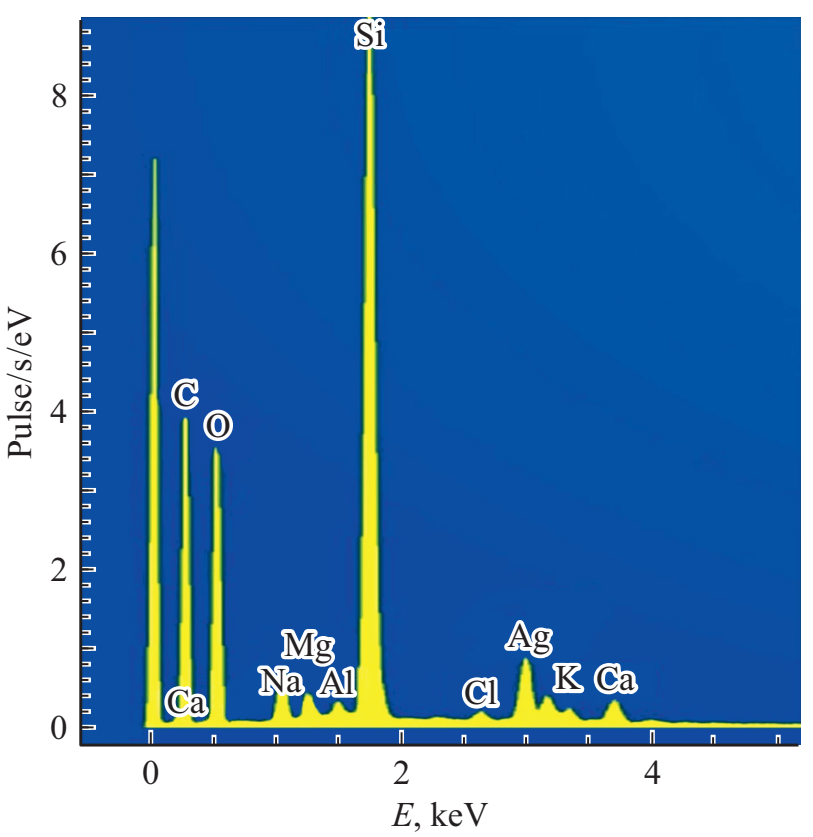

Рис. 3. Энергодисперсионный спектр облученного участка образца. $D=20 \mathrm{~J} / \mathrm{mm}^{2}$.

указывающие на присутствие на поверхности стекла серебра и углерода. При увеличении дозы облучения амплитуда этих пиков увеличивается. Остальные пики на рис. 3 соответствуют компонентам стекла.

Образование наночастиц серебра при лазерном воздействии подтверждают электронно-микроскопические изображения облученных участков образцов (рис. 4). Из рисунка видно, что при $D=4 \mathrm{~J} / \mathrm{mm}^{2}$ наночастицы серебра расположены в основном на значительном рас- 

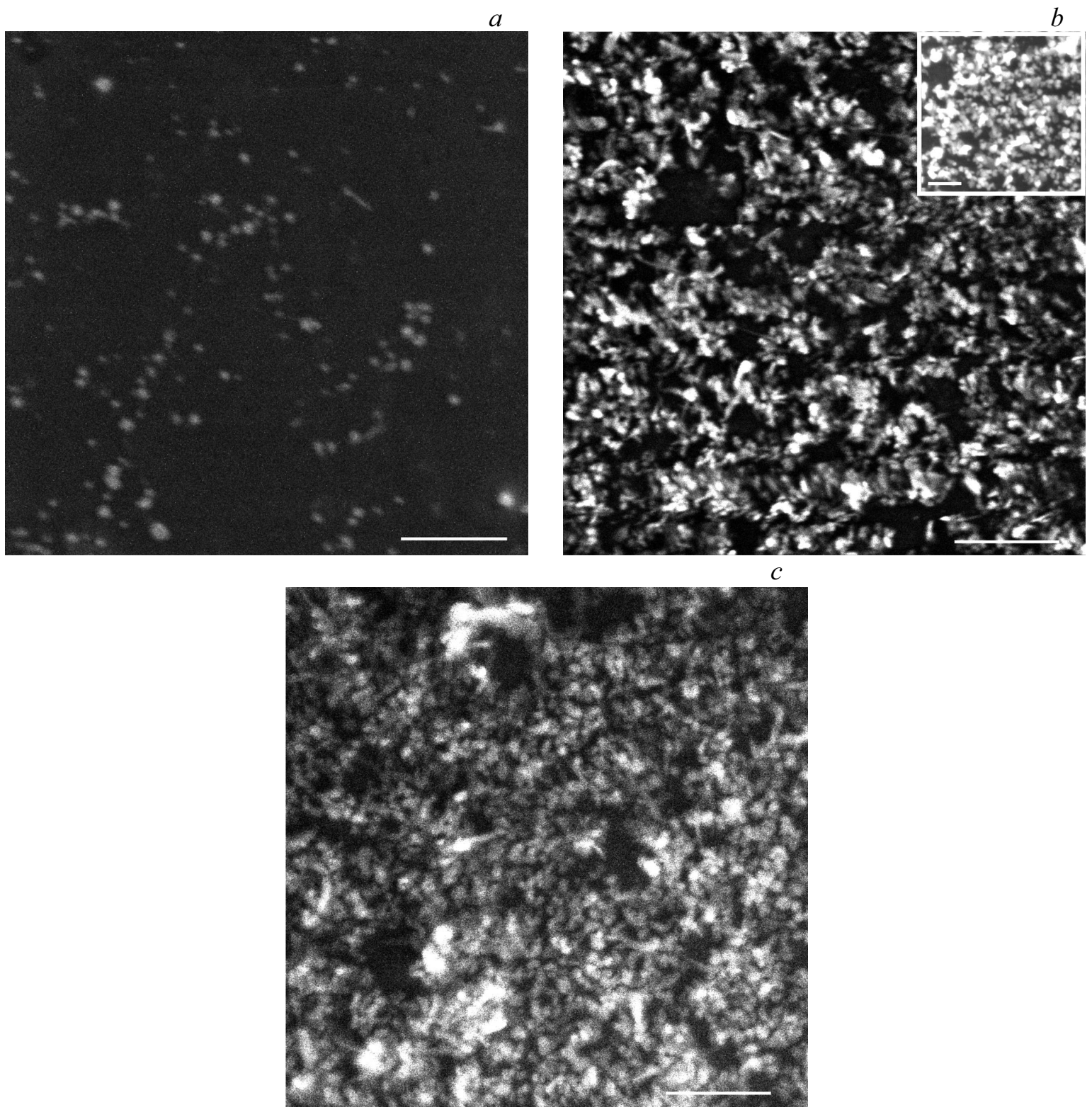

Рис. 4. Электронно-микроскопические изображения облученных участков образцов. $a-D=4 \mathrm{~J} / \mathrm{mm}^{2}, b-20, c-40$. Масштаб $1 \mu \mathrm{m}$. Масштаб во вставке $200 \mathrm{~nm}$.

стоянии друг от друга и образуют монослой. Наночастицы серебра имеют форму, близкую к сферической. При увеличении дозы облучения концентрация наночастиц серебра увеличивается. Как видно из рис. $4, b$ и $c$, группы наночастиц серебра начинают образовывать трехмерные фрактальные кластеры, в состав которых входит до 30 наночастиц. Очевидно, что в этом случае между наночастицами серебра возникает сильное электромагнитное взаимодействие и могут возникать „горячие точки“ [36]. Распределение наночастиц серебра по размерам для трех доз облучения показано на рис. 5 .

Как следует из рисунка, при малой дозе облучения наночастицы размером 20-40 nm имеют максимальную концентрацию. В то же время в облученной зоне присутствуют более крупные наночастицы, размер кото- рых достигает $90 \mathrm{~nm}$. При увеличении дозы облучения возрастает концентрация наночастиц размером менее $20 \mathrm{~nm}$, а концентрация наночастиц, имеющих размер более $40 \mathrm{~nm}$, уменьшается.

Зависимость концентрации наночастиц от дозы облучения показана на рис. 6. Из рисунка следует, что при увеличении дозы облучения до $20 \mathrm{~J} / \mathrm{mm}^{2}$ зависимость близка к линейной. При бо́льших дозах облучения происходит насыщение.

После облучения в облученной зоне возникает люминесценция в синей области спектра с максимумом на длине волны $450 \mathrm{~nm}$ (рис. 7). Такая люминесценция характерна для углеродных квантовых точек, имеющих структуру, подобную структуре графита [37-39]. 

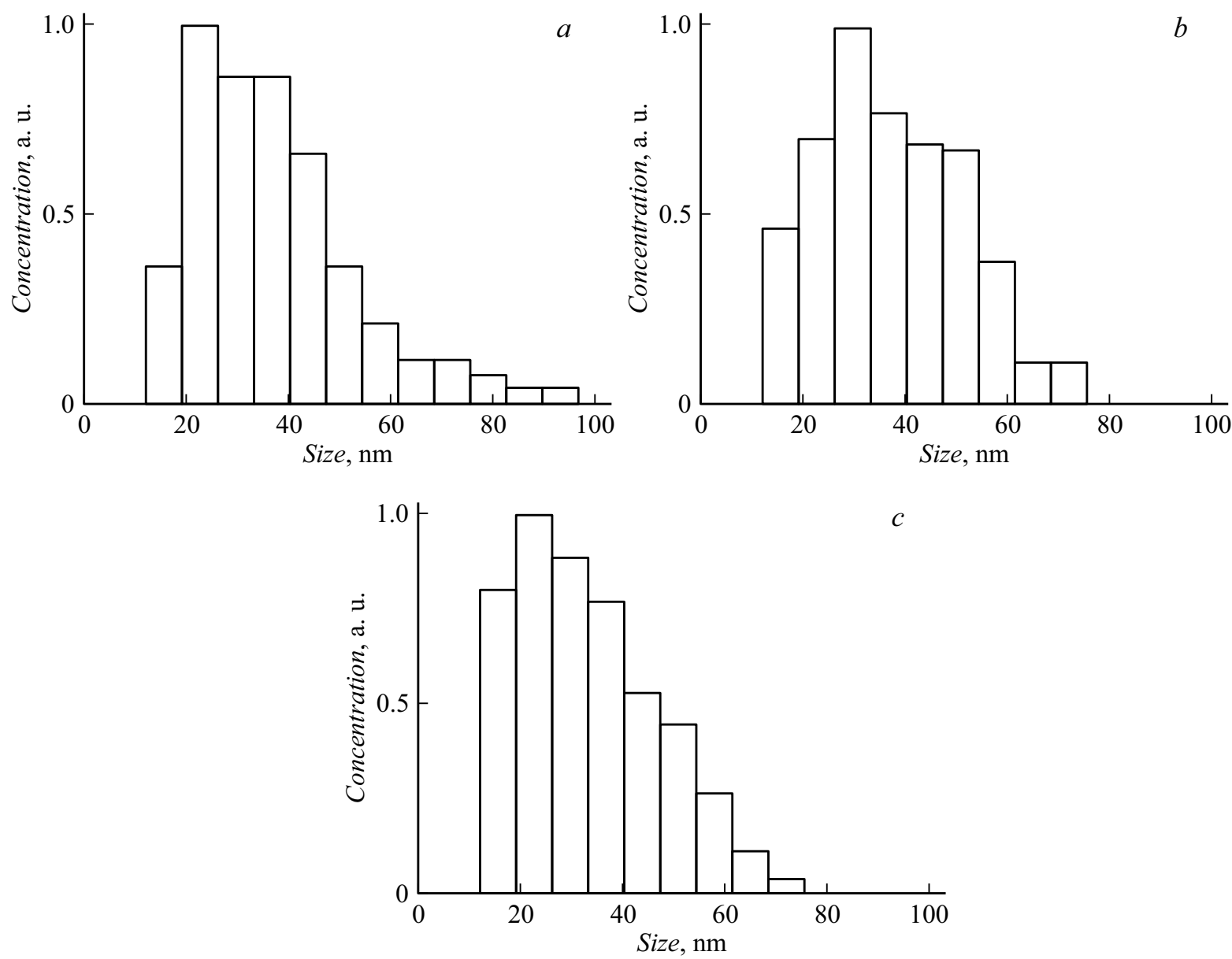

Рис. 5. Нормированное распределение наночастиц серебра по размерам после облучения с дозой: $a-D=4 \mathrm{~J} / \mathrm{mm}^{2}, b-20$, $c-40$.

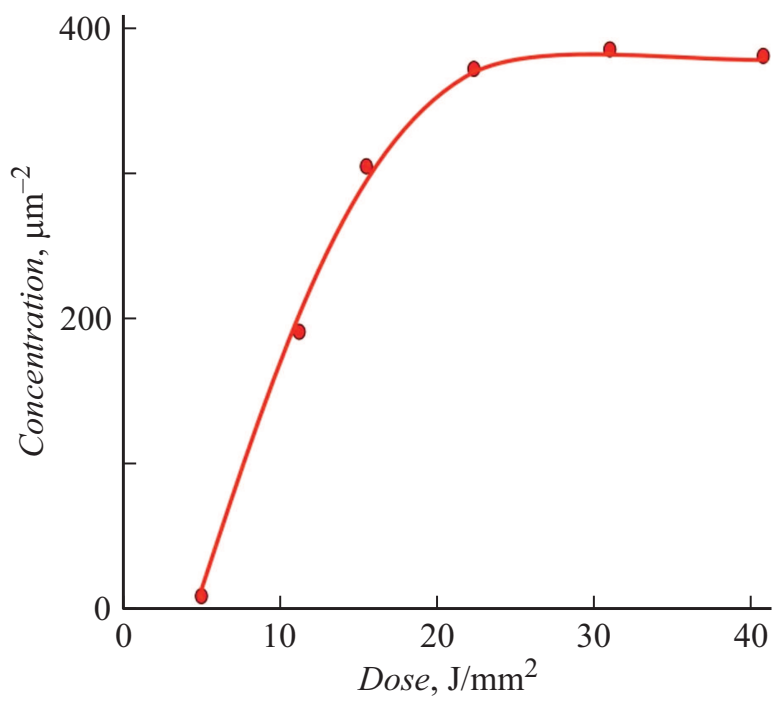

Рис. 6. Зависимость концентрации наночастиц серебра от дозы облучения.

Наличие люминесценции в облученной зоне подтверждает результат энергодисперсионного анализа о присутствии в облученной зоне углерода. Результаты, аналогичные описанным выше, были также получены при замене ПВС на глицерин.

\section{3. Обсуждение результатов}

Таким образом, при воздействии непрерывного лазерного излучения на водный раствор $\mathrm{AgNO}_{3}$ и ПВС происходит формирование наночастиц серебра, обладающих плазмонным резонансом, и углеродных квантовых точек, обладающих люминесценцией. Причиной образования наночастиц серебра является фотолиз соли серебра лазерным излучением. Однако ионы серебра $\mathrm{Ag}^{+}$не способны сформировать наночастицу из-за сил кулоновского отталкивания. Можно предположить, что происходит формирование заряженных молекулярных кластеров серебра $\mathrm{Ag}_{n}^{+}[40,41]$, которые являются зародышами для роста наночастиц. И у них есть возможность захвата электронов у радикалов оксидов азота, которые возникают при фотолизе соли серебра, и у продуктов фотодеструкции ПВС. Это позволяет им перейти в нейтральное состояние и захватывать новые ионы серебра. Причиной образования углеродных квантовых 


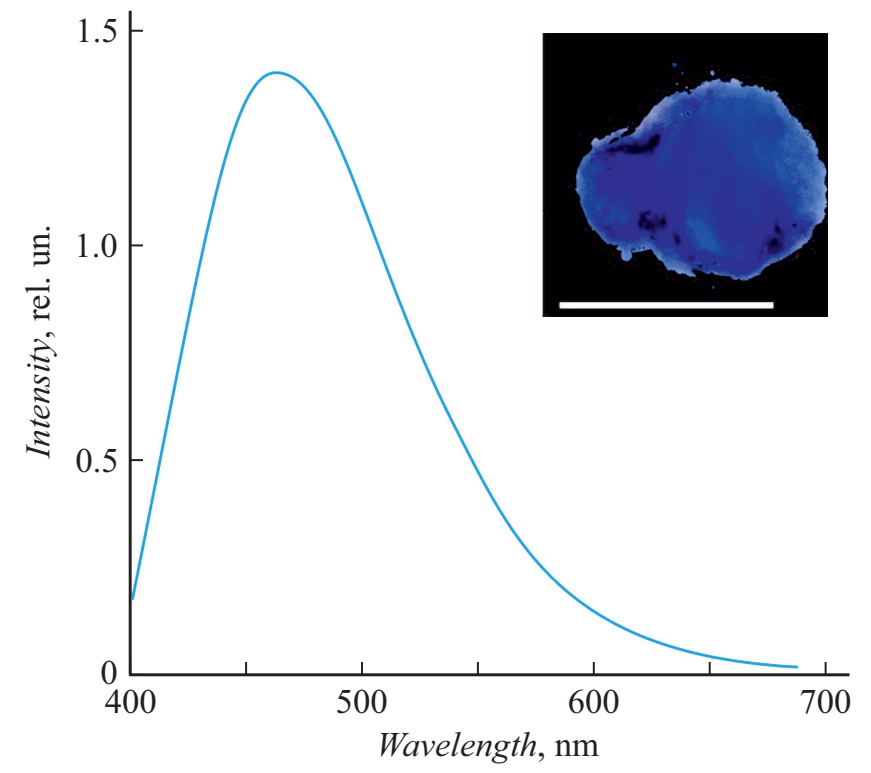

Рис. 7. Спектральная зависимость люминесценции в облученной зоне. $D=20 \mathrm{~J} / \mathrm{mm}^{2}$. Длина волны возбуждения $390 \mathrm{~nm}$. На вставке - фотография люминесценции в облученной зоне. Масштаб $1 \mathrm{~mm}$. Длина волны возбуждения $405 \mathrm{~nm}$.

точек может быть прямое термическое разложение ПВС лазерным излучением. Однако термическое разложение ПВС происходит при температуре $220-230^{\circ} \mathrm{C}$. В то же время известно, что при плазмонном резонансе металлических наночастиц происходит локальное усиление амплитуды поля электромагнитной волны $[14,15]$. Это приводит к локальному увеличению температуры вблизи наночастицы и может способствовать термическому разложению ПВС в тонком слое, окружающем наночастицу. Кроме того, как было показано выше, при больших дозах облучения наночастицы образуют фрактальные кластеры. В таких кластерах могут возникать „горячие точки“, в которых усиление амплитуды поля электромагнитной волны может значительно, в сотни раз, превышать усиление поля вблизи отдельной наночастицы. В результате этого эффективность термического разложения ПВС с образованием углеродных квантовых точек повышается. Таким образом, можно сделать вывод, что углеродные квантовые точки возникают уже после образования наночастиц серебра. Образование наночастиц серебра вокруг облученной зоны связано рассеянием лазерного излучения как в слое жидкости, так и на уже сформировавшихся наночастицах серебра.

Возникновение фрактальных кластеров из наночастиц серебра можно объяснить следующим. При плазмонном резонансе, нагреве наночастицы и окружающего слоя жидкости на поверхности наночастицы возникают микропузырки газа [42]. Это приводит к перемещению наночастиц, и у них появляется возможность собираться в кластеры. Вклад в этот процесс может вносить также кавитация облучаемой зоне.
Как видно из рис. 5, при увеличении дозы облучения доля наночастиц малого размера увеличивается. Причиной этого может быть то, что при формировании кластеров из наночастиц уменьшается вероятность захвата наночастицей, входящей в кластер, ионов серебра, необходимых для ее роста, так как вблизи кластера происходит обеднение раствора необходимым материалом. Обеднение раствора ионами серебра в облученной зоне является также причиной насыщения (рис. 6). При малых дозах облучения ионы серебра успевают диффундировать из окружающего раствора в область воздействия лазерного луча. При больших дозах раствор вокруг облученной зоны обедняется серебром, и происходит насыщение.

\section{Заключение}

Эксперименты показали, что при фотолизе $\mathrm{AgNO}_{3}$ в растворе ПВС непрерывным лазерным излучением на поверхности стеклянной подложки формируются наночастицы серебра, обладающие плазмонным резонансом, и углеродные квантовые точки, обладающие люминесценцией. Средний размер наночастиц серебра составляет $10-50 \mathrm{~nm}$ и зависит от дозы облучения. Наночастицы серебра имеют форму, близкую к сферической. При дозе облучения $D \geq 20 \mathrm{~J} / \mathrm{mm}^{2}$ наночастицы серебра образуют трехмерные фрактальные кластеры. Образование углеродных квантовых точек вызвано локальным нагревом раствора вблизи наночастицы серебра в условиях плазмонного резонанса и возможного появления горячих точек во фрактальных кластерах, состоящих из наночастиц серебра.

\section{Благодарности}

Лазерное облучение образцов было выполнено в СПбГЭТУ „ЛЭТИ“. Обработка и анализ результатов проводились в Университете ИТМО.

\section{Финансирование работы}

Работа выполнена при финансовой поддержке Российского научного фонда (проект № 20-19-00559).

\section{Конфликт интересов}

Авторы заявляют, что у них нет конфликта интересов.

\section{Список литературы}

[1] W. Zhou, J.D. Mandia, M. Griffiths, A. Bialiayeu, Y. Zhang, P.G. Gordon, S.T. Barry, J. Albert. J. Opt. Expr., 21, 245 (2013).

[2] C.K. Tagada, S.R. Dugasani, R. Aiyer, S. Park, A. Kulkarni, S. Sabharwal. Sens. Act. B: Chem., 183, 144 (2013). 
[3] A.V. Nashchekin, V.N. Nevedomskiy, P.A. Obraztsov, O.V. Stepanenko, A.I. Sidorov, O.A. Usov, K.K. Turoverov, S.G. Konnikov. Proc. SPIE, 8427, 842739 (2012).

[4] S. Choi, R.M. Dicksonc, J. Yu. Chem. Soc. Rev., 41, 1867 (2012).

[5] R. Yang, Z. Lu. Int. J. Opt., 2012, 1 (2012).

[6] P. Hewageegana, M.I. Stockman. Infrared Phys. Tech., 50, 177 (2006).

[7] C.W. Tseng, Y.L. Chen, Y.T. Tao. Org. Electr., 13, 1436 (2012).

[8] X.R. Jin, Y. Lu, H. Zheng, Y.P. Lee, J.Y. Rhee, K.W. Kim, W.H. Jang. Opt. Commun., 284, 4766 (2011).

[9] A. Normatov, P. Ginzburg, N. Berkovitch, G.M. Lerman, A. Yanai, U. Levy, M. Orenstein. Opt. Expr., 18, 14079 (2010).

[10] R. Chang, H.P. Chiang, P.T. Leung, D.P. Tsai, W.S. Tse. Sol. St. Commun., 133, 315 (2005).

[11] M.R. Singh. Superlat. Microstr., 43, 537 (2008).

[12] N.C. Lindquist, P. Nagpal, K.M. McPeak, D.J. Norris, S.H. Oh. Rep. Prog. Phys., 75, 161 (2012).

[13] M.A. Garcia. J. Phys. D: Appl. Phys., 44, 1 (2011).

[14] В.В. Климов. Наноплазмоника (Физмалит, М., 2010) [V.V. Klimov. Nanoplasmonics (Pan Stanford, Singapore, 2014)]

[15] U. Kreibig, M. Vollmer. Optical Properties of Metal Clusters (Springer-Verlag, Berlin, 1995)

[16] Л.А. Дыкман, В.А. Богатырев, С.Ю. Щеголев, Н.Г. Хлебцов. Золотые наночастицы: синтез, свойства, биомедииинское применение (Наука, М., 2008)

[17] С.В. Карпов, В.В. Слабко. Оптические и фотобизические свойства фрактальноструктурированных золей металлов (СО РАН, Новосибирск, 2003)

[18] S. Amoruso, G. Ausanio, R. Bruzzese, M. Vitiello, X. Wang. Phys. Rev. B., 71, 033406 (2005).

[19] В.И. Егоров, А.В. Нащекин, А.И. Сидоров. Квант. электр., 45, 858 (2015). [V.I. Egorov, A.V. Nashchekin, A.I. Sidorov. Quant. Electr., 45, 840 (2015).]

[20] В.И. Егоров, И.В. Звягин, Д.А. Клюкин, А.И. Сидоров. Опт. журн., 81 (5), 54 (2014). [V.I. Egorov, I.V. Zvyagin, D.A. Klyukin, A.I. Sidorov. J. Opt. Techn., 81, 270 (2014).]

[21] S.L. Stoll, E.G. Gillan, A.R. Barron. Chem. Vap. Depos., 2, 182 (1996).

[22] Y. Kaganovskii, E. Mogilko, A.A. Lipovskii, M. Rosenbluh. J. Phys.: Conf. Ser., 61, 508 (2007).

[23] П.А. Образцов, А.В. Нащекин, Н.В. Никоноров, А.И. Сидоров, А.В. Панфилова, П.Н. Брунков. ФТТ, 55, 1180 (2013). [P.A. Obraztsov, A.V. Nashchekin, N.V. Nikonorov, A.I. Sidorov, A.V. Panfilova, P.N. Brunkov. Phys. Sol. St., 55, 1272 (2013).]

[24] T. Tanaka. J. Laser Micro/Nanoeng., 3, 152 (2008).

[25] L. Liu, D. Yang, W. Wan, H. Yang, Q. Gong, Y. Li. Nanophot., 8, 1087 (2019).

[26] K. Kaneko, H. Sun, X. Duan, S. Kawata. Appl. Phys. Lett., 83, 1426 (2003).

[27] B. Xu, H. Xia, L. Niu, Y. Zhang, K. Sun, Q. Chen, Y. Xu, Z. Lu, Z. Li, H. Misawa, H. Sun. Small., 6, 1762 (2010).

[28] M. Focsan, A.M. Craciun, S. Astilean, P.L. Baldeck. Opt. Mater. Expr., 6, 1587 (2016).

[29] Z. Ma, Y. Zhang, B. Han, Q. Chen, H. Sun. Small Meth., 2, 1700413 (2018).

[30] A. Vyatskikh, S. Delalande, A. Kudo, X. Zhang, C.M. Portela, J.R. Greer. Natur. Commun., 9, 593 (2018).
[31] E. Blasco, J. Múller, P. Müller, V. Trouillet, M. Schön, T. Scherer, C. Barner-Kowollik, M. Wegener. Adv. Mater., 28, 3592 (2016).

[32] T. Baldacchini, A. Pons, J. Pons, C.N. La Fratta, J.T. Fourkas, Y. Sun, M.J. Naughton. Opt. Expr., 13, 1275 (2005).

[33] Y. Cao, N. Takeyasu, T. Tanaka, X. Duan, S. Kawata. Small., 5, 1144 (2009).

[34] S. Kang, K. Vora, E. Mazur. Nanotechn., 26, 121001 (2015).

[35] T. Komori, T. Furukawa, M. Iijima, S. Maruo. Opt. Expr., 28, 8363 (2020).

[36] M.I. Stockman. Electromagnetic theory of SERS. In: K. Kneipp, M. Moskovits, H. Kneipp (eds.). Surface-Enhanced Raman Scattering (Springer, NY., 2006)

[37] M.C. Ortega-Liebana, J.L. Hueso, S. Ferdousi. Diamond Relat. Mater., 65, 176 (2016).

[38] D.K. Nelson, B.S. Razbirin, A.N. Starukhin. Opt. Mater., 59, 28 (2016).

[39] S. Zhu, Q. Meng, L. Wang. Angew. Chem. Int. Ed., 52, 3953 (2013).

[40] М.В. Столярчук, А.И. Сидоров. Опт. и спектр., 125, 291 (2018). [M.V. Stolyarchuk, A.I. Sidorov. Opt. Spectr., 125, 305 (2018).]

[41] V. Bonačič-Koutecký, J. Pittner, M. Boiron, P. Fantucci. J. Chem. Phys., 110, 3876 (1999).

[42] G. Baffou, J. Polleux, H. Rigneault, S. Monneret. J. Phys. Chem., 118, 4890 (2014). 